\title{
The US-preexposure effect in honeybees
}

\author{
CHARLES I. ABRAMSON and M. E. BITTERMAN \\ University of Hawaii, Honolulu, Hawaii
}

\begin{abstract}
Signaled avoidance was studied in individual honeybees that visited the laboratory regularly to take sucrose solution from a target set on the sill of an open window. During feeding, substrate vibration or airstream was used to signal a brief shock that could be avoided by breaking off contact with the food for a few seconds. Aversive conditioning of the context was measured in terms of return time (the time between successive visits). In Experiment 1, experience with unsignaled shock was found to lengthen return time-which experience with signaled shock did not-and to impair performance in subsequent avoidance training with signaled shock (the USpreexposure effect). In Experiment 2, experience with unsignaled shock given after signaled avoidance training lengthened return time but had no effect on response to the signal in a subsequent extinction test. These results closely resemble the results obtained in analogous experiments with vertebrates.
\end{abstract}

While developing a technique for the study of signaled avoidance in honeybees, described recently by Abramson (1986), we made some informal observations which suggested that excitatory conditioning is retarded by prior experience either with the conditioned stimulus (CS) alone or with the unconditioned stimulus (US) alone. Both phenomena are well known in vertebrates-the first as latent inhibition (Lubow, 1973), the second as the USpreexposure effect (Randich \& LoLordo, 1979) - and have important implications for vertebrate learning theory. In subsequent formal experiments with honeybees (Abramson \& Bitterman, 1986), we were able to demonstrate not only that a stimulus is in fact slower to acquire excitatory properties after unreinforced preexposure, but that it actively suppresses response to a conditioned excitor presented with it. The summation results were different from those usually reported for vertebrates (e.g., Reiss \& Wagner, 1972; Rescorla, 1971), which have been taken to mean that retarded acquisition is due to reduced salience or associability of the CS rather than to inhibition or to response competition, although results much like ours have been obtained at least in one experiment with rats (Kremer, 1972). The discrepancies-between our results and the modal vertebrate results, and between Kremer's results and the modal vertebrate results-remain to be investigated. An interesting aspect of the problem is that work with nonmammalian vertebrates has not clearly established latent inhibition as a general phenomenon of vertebrate learning (Shishimi, 1985). If the mechanisms of latent inhibition in honeybees and mammals have evolved independently, they may well be somewhat different.

This research was supported by Grant No. BNS 83-17051 from the National Science Foundation. C. I. Abramson is now in the Department of Biochemistry, Downstate Medical Center, SUNY, 450 Clarkson Avenue, Brooklyn, NY 11203. Requests for reprints should be addressed to M. E. Bitterman, Békésy Laboratory of Neurobiology, 1993 East-West Road, Honolulu, HI 96822.
We turn now (in this continuing survey of learning in honeybees from the perspective of work with vertebrates) to the US-preexposure effect. Whatever its complexities (Balsam, 1985), there is convincing evidence that the USpreexposure effect in vertebrates is due in large measure to contextual conditioning (e.g., Ayres, Bombace, Shurtleff, \& Vigorito, 1985; Balsam \& Schwartz, 1981; Grau \& Rescorla, 1984; Hinson, 1982; Randich \& Ross, 1984), and we were led by that evidence to look for contextual conditioning as we attempted a formal demonstration of the effect in honeybees. In our conditioning procedure, a stimulus is paired with a brief shock while the subject, a free-flying forager, is feeding from a well of sucrose solution in the center of a distinctive target. The animal can avoid the shock simply by withdrawing its proboscis from the food, but what almost always happens is that the animal flies off the target for a few seconds, after which it settles down and resumes feeding to repletion. Since the animal comes to the target of its own accord, shuttling back and forth between the hive and the laboratory, the return time (the time between leaving the target at the end of one visit and landing again on the next) seems to afford a good measure of the attractiveness of the target, which may be enhanced by association with food and reduced by association with shock. Abramson (1986) found that return time increases substantially in the course of training with signal and shock explicitly unpaired, but hardly at all in the course of paired training, suggesting stronger aversive conditioning of the context in the unpaired case (either because contextual stimuli are overshadowed by the signal in the paired case, or because a good many shocks are avoided, or both).

\section{EXPERIMENT 1}

In the first stage of this experiment, we used four groups: one unstimulated, the second trained with shock alone, the third trained with signaled shock, and the fourth 
trained like the second with unsignaled shock but yoked with the third to control for shock frequency. In the second stage of the experiment, all groups were trained with signaled shock, the third group with a signal different from that previously encountered. The purpose of the first two groups was to look for formal evidence of the USpreexposure effect and for some indication that it might be related to contextual conditioning. The purpose of the third group was to test the hypothesis that signaling the shock would reduce contextual conditioning and therefore reduce the US-preexposure effect, as it often has been found to do in vertebrate experiments (Baker, Mercier, Gable, \& Baker, 1981; Grau \& Rescorla, 1984; Randich, 1981). The fourth group controlled for the possibility that signaling might be effective simply because of reduced frequency of shock.

\section{Method}

Subjects. The subjects were $\mathbf{4 8}$ honeybees (Apis mellifera) from our own hives situated in the immediate vicinity of the laboratory.

Apparatus. Presented on the shelf of an open laboratory window was a target made of a petri dish $(5.5 \mathrm{~cm}$ in diameter) with a copper plate $(5 \mathrm{~cm}$ in diameter) mounted on its cover. In the center of the target was an insulated food well $(1 \mathrm{~cm}$ in diameter and $.5 \mathrm{~cm}$ deep) filled with $50 \%$ sucrose solution. When a honeybee was standing on the copper plate (which was necessary in order to feed) and its proboscis was in contact with the sucrose solution, a pulse of shock ( $25 \mathrm{~V} \mathrm{ac}, 35 \mathrm{msec}$ duration) could be delivered (the copper plate being connected to one side of the supply and the sucrose solution to the other). Two conditioned stimuli-substrate vibration and airstream-were used. To generate the former, the target was mounted on a vibrator (Goodman Industries, Wembley, England) set to produce a frequency of $50 \mathrm{~Hz}$ and a peak-to-peak amplitude of $.15 \mathrm{~mm}$. To generate the latter, a second petri dish of the same size was mounted above the target at the height of $2.5 \mathrm{~cm}$. Drilled in its bottom were a series of 46 small holes through which compressed air ( $7.5 \mathrm{psi}$ ) could be directed upon the animal below. A solenoid valve was used to turn the airstream on and off. The two stimuli condition rapidly and are readily discriminable (Abramson, 1986; Abramson \& Bitterman, 1986).

Procedure. The work was done with marked individuals, experimentally naive, which were trained in a single session. They were selected at random from a group of foragers at a feeding station providing $10 \%-15 \%$ sucrose solution. A single animal was picked up in a small matchbox, carried to the target, and set down at the food well. While the animal was feeding, it was marked with a spot of colored lacquer, and after it finished feeding it was free to leave for the hive. Typically, the bee returned to the target within a few minutes, but if not, it was recaptured at the feeding station (where it usually could be found) and placed again on the target. The pretraining ended with the subject's first return to the laboratory of its own accord, after which it could be counted on to shuttle regularly back and forth between the hive and the laboratory. As the experiment progressed, animals were assigned in quasirandom fashion to four groups of 12 subjects each: control, US, signal, and yoke.

The first stage of the experiment consisted of 10 visits for the animals of the control group and the US group. The animals of the control group were undisturbed, but the animals of the US group received an unsignaled shock 10 or $35 \mathrm{sec}$ (in balanced quasi-random order) after the start of feeding on each visit. The animals of the signal group and of the yoke group had 20 visits instead of 10 visits in the first stage of the experiment, in order to ensure a substantial frequency of shock. For the signal animals, the shock scheduled on each visit (again at 10 or $35 \mathrm{sec}$ after the start of feeding, in balanced order) was preceded by a 5-sec signal (vibration for half the subjects and airstream for the rest) and therefore could be avoided. For each signal animal, there was a yoke animal that was given an unsignaled shock at whatever point in the training the signal animal failed to avoid. The second stage of training consisted of 10 visits for all groups, which were treated exactly alike. On each visit, 5 or $30 \mathrm{sec}$ after the start of feeding, there was a signaled avoidance trial with $5 \mathrm{sec}$ of vibration for half the subjects in each group and $5 \mathrm{sec}$ of airstream for the rest. For the signal animals, the conditioned stimulus used in the second stage was different from that used in the first stage (airstream in the second stage if vibration had been used in the first stage, and vice versa).

\section{Results}

Plotted in Figure 1 are the mean $\ln$ (natural log) return times (in seconds) of the four groups on the first 10 visits in the first stage of the experiment. (The return time for the first visit is the time between the last pretraining visit and the first visit in the first stage of training-the first visit on which shock was scheduled for all groups except the control group.) As the curves show, the return times declined progressively to a low level in the control and signal groups, declined progressively to an intermediate le vel in the yoke group, and declined only temporarily in the US group, soon regressing to a higher level. These results suggest that unsignaled shock produces aversive conditioning of the context that competes with appetitive conditioning and is reflected in reluctance to return to the context; that the strength of aversive conditioning varies with the density of unsignaled shock (because the signal animals could avoid, the yoke animals received only about four shocks on the average in the first 10 visits); and that signaling shock reduces aversive conditioning of the context.

Analysis of variance provides statistical support for these conclusions: In the overall analysis, $F(3,44)$ for groups $=5.75, p=.0021$, and $F(3,44)$ for the interaction of groups $\times$ five-visit blocks $=3.28, p=.0292$.

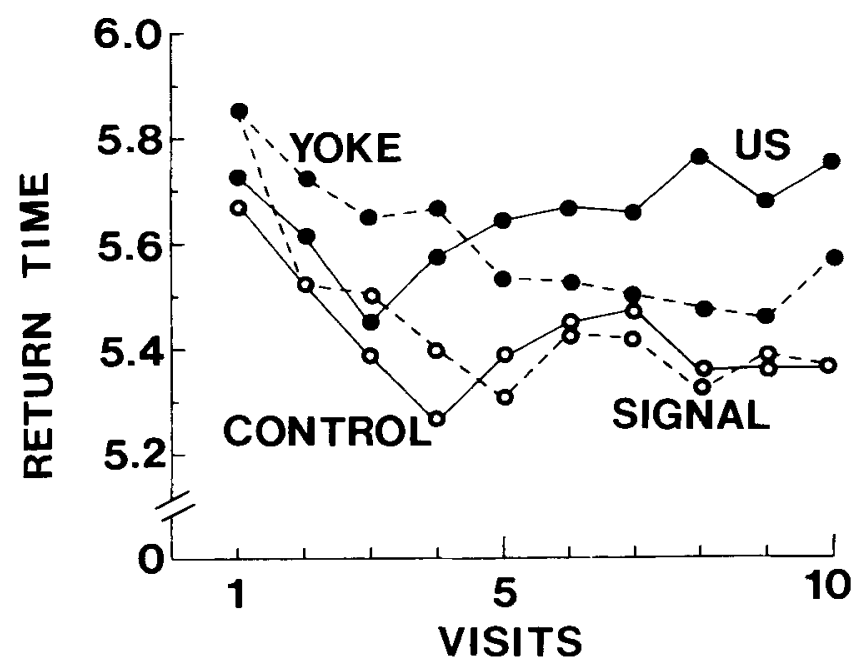

Figure 1. Mean In (natural $\log$ ) return times (in seconds) for the first 10 visits of Experiment 1. 
Comparison of the US and control groups shows a significant groups effect $[F(1,22)=11.48, p=.0026]$. Comparison of the US and yoke groups shows no significant groups effect $[F(1,22)=1.44, p=.2427]$, but a significant groups $\times$ blocks interaction $[F(1,22)=5.97$, $p=.0230]$. Comparison of the signal and yoke groups shows a significant groups effect $[F(1,22)=4.52, p=$ $.0451]$, but comparison of signal and control groups does not $(F<1)$.

In the next 10 visits, during which the treatment of the signal and yoke groups was the same as in the first 10 , their mean In return times remained much the same as shown in the right-hand portion of Figure 1, but the variability in the times for the yoke group was such that the groups effect was not significant $[F(1,22)=1.38, p=$ $.2529]$. The frequency of unsignaled shock, which continued to be low ( 3.6 shocks on the average in the second 10 visits), apparently was not sufficient to sustain a measurable aversive influence.

The return times for the US and control groups in the second stage of the experiment, when both were trained with signaled shock, are plotted in Figure 2 . As the curve of the US group shows, its return times declined progressively. In the case of the control group, shock on the first visit seemed to delay the next visit, but the return times thereafter remained at about the level established in the prior training. Analysis of variance does not yield a significant groups effect $[F(1,22)=2.81, p=.1081]$, but does yield a significant (five-visit) blocks effect $[F(1,22)$ $=11.35, p=.0028]$. The complexity of the pattern of differential change is reflected in a significant interaction of groups $\times$ blocks $\times$ visits $[F(4,88)=4.22, p=.0036]$.

In Figure 3, the performance of the US and control groups in the second stage of the experiment is plotted in terms of the proportion of animals responding to the CS on each visit. The curve for the control group shows the rapid conditioning that we have seen before (Abram-

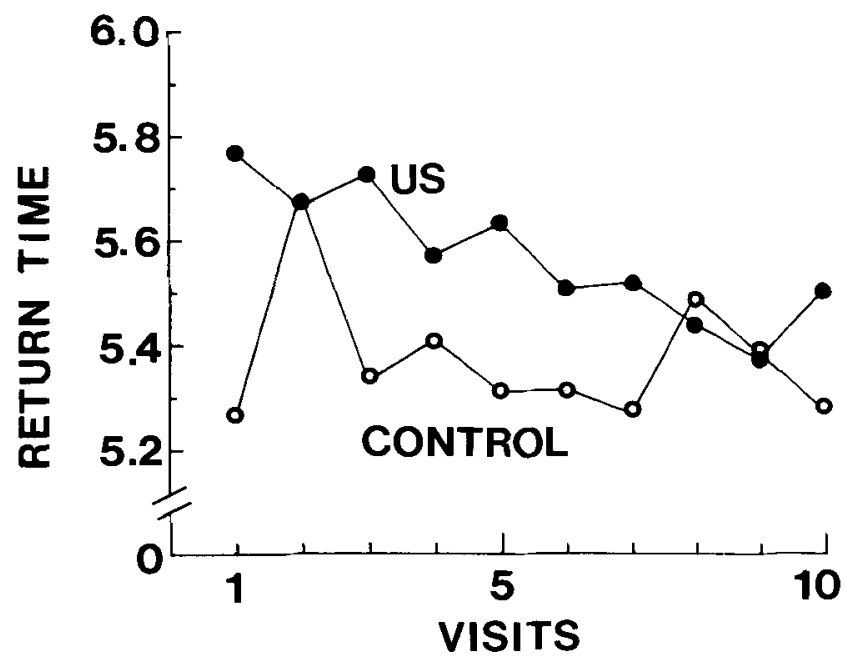

Figure 2. Mean In return times (in seconds) of the US and control groups in the second stage of Experiment 1.

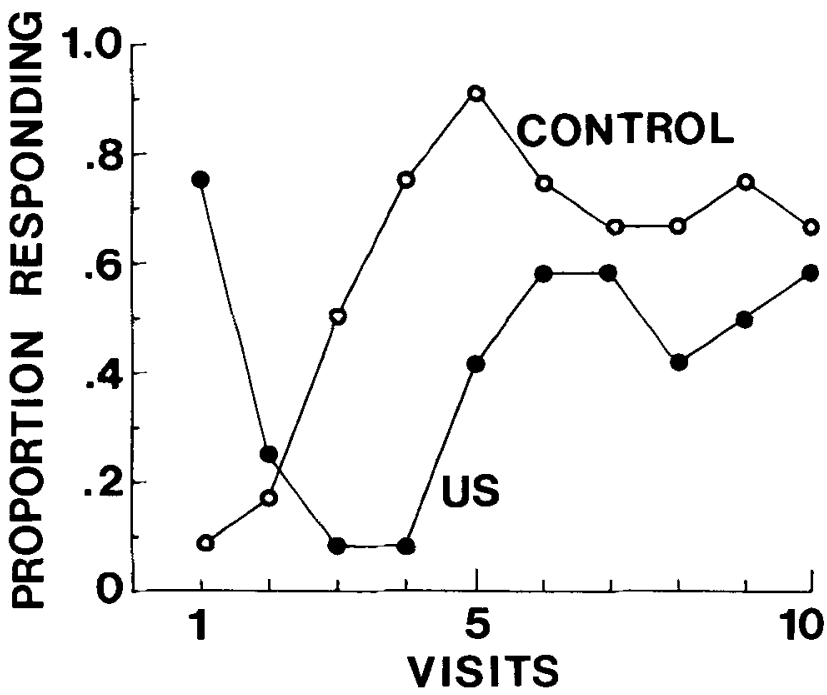

Figure 3. Proportion of animals in the US and control groups responding to the signal on each visit in the second stage of Experiment 1.

son \& Bitterman, 1986), whereas the curve for the US group shows retardation-the US-preexposure effect familiar from the study of vertebrates. Analysis of variance based on the number of avoidances by each animal in each block of five visits yields a significant groups effect $[F(1,22)=7.17, p=.0138]$. An interesting feature of the performance of the US group, which we saw also in our pilot data, is the high proportion of animals responding to the signal on its first presentation: 9 of the 12 US animals responded, but only 1 of the control animals, a difference which Fisher's exact test shows to be highly significant $(p=.0013)$. Response to the signal seems, then, to have been sensitized by the experience with unsignaled shock, although conditioning was retarded. Since an avoidance contingency was in operation, response to the signal on the first trial prevented pairing with shock, but that probably is not sufficient to account for the retardation. Signal and shock were paired for 9 of the 12 US animals on the second conditioning visit, and for 11 of them on the third, yet only 1 responded to the signal on the fourth visit.

In Figure 4, the performance of the signal and yoke groups in the second stage of the experiment is plotted in terms of the proportion of animals responding to the signal on each visit. Although previous work had shown vibration and airstream to be readily discriminable when differentially reinforced (Abramson, 1986; Abramson \& Bitterman, 1986), the signal animals generalized readily and continued in the course of the subsequent reinforced training to respond to the new stimulus at the same level as to the old. (It should be noted that the mean asymptotic level of performance produced by our conditioning procedure typically is only about $70 \%$, not because some animals fail to condition, but because successful avoidance continues to weaken the tendency to respond to the signal; although the contingency is instrumental, the condi- 


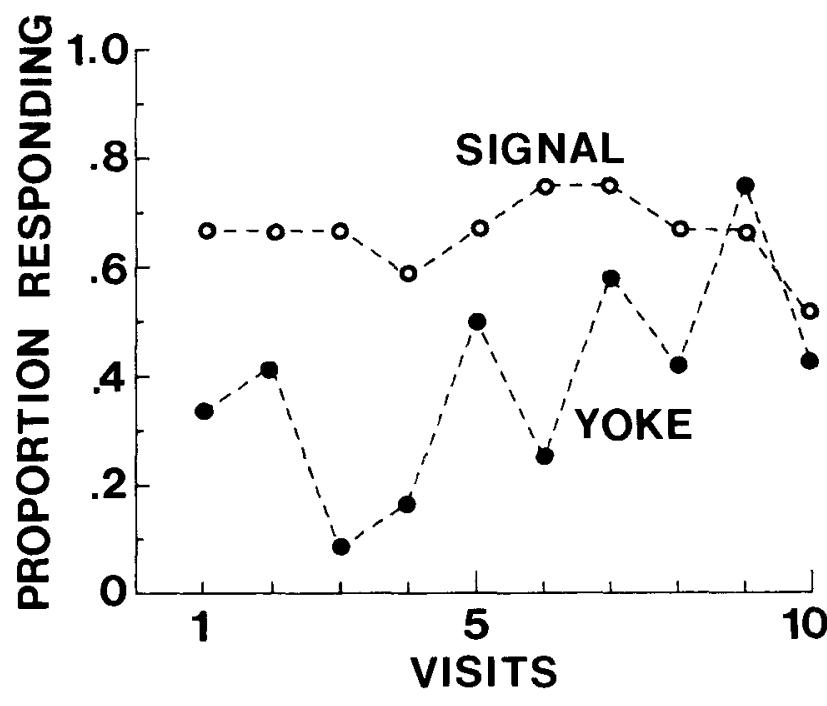

Figure 4. Proportion of animals in the signal and yoke groups responding to the signal on each visit in the second stage of Experiment 1.

tioning process may be purely classical.) Although we were looking only for better performance in the signal group than in the yoke group, which of course we found $[F(1,22)=23.56, p=.0001]$, the performance of the signal group proved to be better even than that of the control group; analysis shows an insignificant groups effect $[F(1,22)=1.64, p=.2140]$, but a significant interaction of groups $\times$ five-visit blocks $[F(1,22)=6.05, p=$ .0223 ]. The results highlight a shortcoming of the design, which is that better performance after training with signaled than with unsignaled shock may be due simply to stimulus generalization, although this possibility may perhaps be discounted if there is a low initial level of response in both groups.

\section{EXPERIMENT 2}

In this experiment, patterned again after work with vertebrates, two groups of bees were conditioned and then one of them was exposed repeatedly to unsignaled shock in the same context. The purpose was to study the influence of contextual conditioning on response to a previously conditioned stimulus. According to the blocking interpretation, the US-preexposure effect is an associative one, to be explained, for example, on the basis of the assumption that the signai must compete with contextual stimuli for associative strength (Rescorla \& Wagner, 1972). In this view, postconditioning presentations of the US-conditioning of contextual stimuli after the signal has been conditioned - should not reduce subsequent response to the signal, and may even facilitate it (summation). Another view (Gibbon \& Balsam, 1981) is that USpreexposure interferes with performance rather than with learning; the probability of response to the signal is assumed to vary inversely with the associative strength of the context, and the expectation, therefore, is that postconditioning exposure of the US will reduce response to the signal. The results of a variety of recent vertebrate experiments tend on the whole to support the associative view. The US-preexposure effect is evidenced in testing contexts that vary widely in associative strength (Ayres et al., 1985; Randich \& Ross, 1984), and postconditioning presentations of the US do not in fact reduce response to a previously conditioned signal (Bouton \& King, 1986; Grau \& Rescorla, 1984).

\section{Method}

Subjects. The subjects were 24 honeybees from our own hives situated in the vicinity of the laboratory.

Apparatus and Procedure. The apparatus was the same as that used in the previous experiment, and the pretraining procedure also was the same. On each of the 5 visits in the first stage of the experiment, there was a single conditioning trial, 5 or $30 \mathrm{sec}$ after the beginning of feeding in balanced quasi-random order. On each trial, a brief avoidable shock was scheduled $5 \mathrm{sec}$ after the onset of the signal, which was vibration for 6 of the 12 animals in each of two groups and airstream for the rest. In the second stage of the experiment, there were 10 visits, on each of which the animals of the US group were given an unsignaled shock 10 or $35 \mathrm{sec}$ after the beginning of feeding in quasi-random order; the animals of the control group were unstimulated. In the third stage of the experiment, there were 5 visits, on each of which, for both groups, there was an unreinforced presentation of the previously conditioned signal. In the fourth stage of the experiment, there were 5 visits, on each of which, for both groups, there was a conditioning trial with the signal not yet encountered (airstream for the animals previously trained with vibration, and vice versa).

\section{Results}

In the first stage of the experiment, both groups conditioned rapidly and at the same rate. In the third stage of the experiment, they extinguished rapidly and at the same rate, showing no effect of postconditioning experience with the unsignaled US. The acquisition and extinction

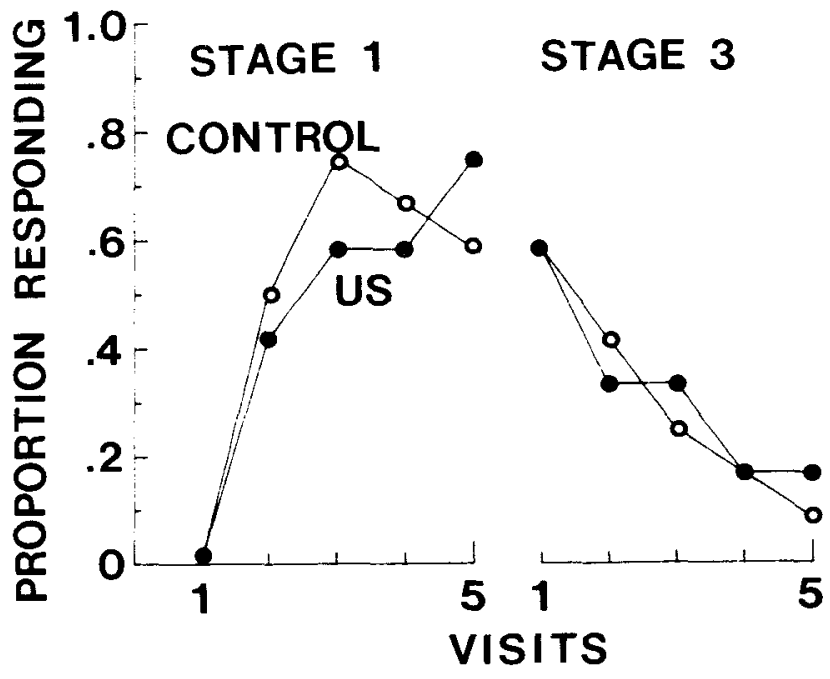

Figure 5. Proportion of animals in the US and control groups responding to the signal on each visit in the first stage (left panel) and the third stage (right panel) of Experiment 2. 


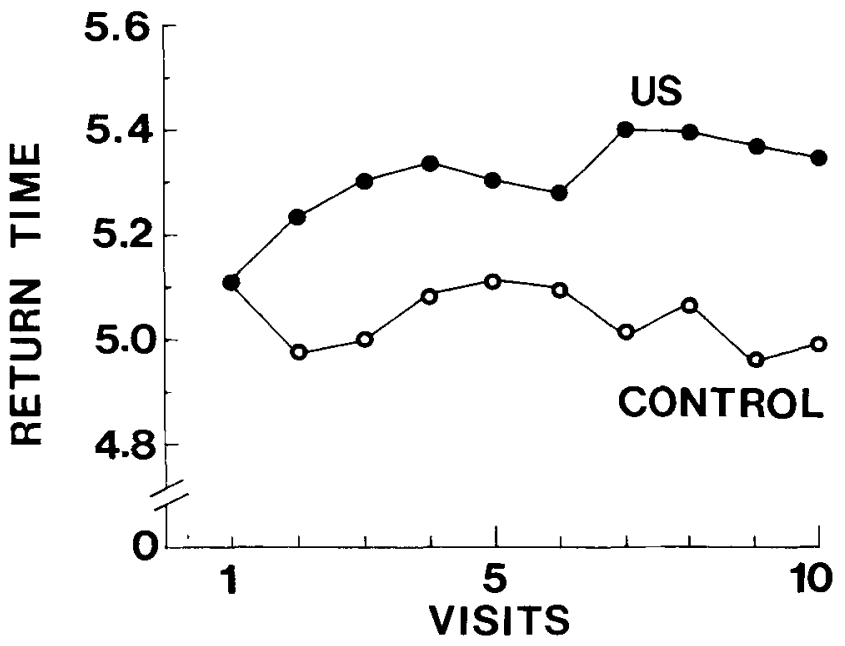

Figure 6. Mean In return times (in seconds) in the second stage of Experiment 2.

curves are plotted in Figure 5 in terms of the proportion of animals in each group that responded to the signal on each visit. There was, nevertheless, clear evidence of contextual conditioning in the US group during the second stage of the experiment. During the first stage, the mean ln return times of the two groups declined to the same low level (somewhat lower than we usually find, it should be noted), but the times diverged during the second stage, increasing progressively in the course of unsignaled experience with the US and not in the series of control visits. The divergence is plotted in Figure 6. Analysis of variance yields a significant groups effect $[F(1,22)=13.52$, $p=.0013]$, and a significant interaction of groups $\times$ fivevisit blocks $[F(1,22)=19.07, p=.0002]$. These results support an associative interpretation of the USpreexposure effect. In the fourth stage of the experiment, acquisition was rapid in both groups-a bit more rapid in the control group, but not significantly so. Because the return times of the US group had declined to the control level by the end of the third stage, indicating that aversion to the context had extinguished, there was no reason to expect different performance in the fourth stage. Like results were obtained in an experiment with rats by Randich (1981), who found that the US-preexposure effect was reduced by unreinforced exposure to the context between preexposure to the US and subsequent conditioning.

\section{DISCUSSION}

As we noted at the outset, some indication of what was known from the vertebrate literature as the USpreexposure effect appeared in our initial explorations of signaled avoidance conditioning in honeybees. There was some indication of it, too, in earlier work on appetitive conditioning (Bitterman, Menzel, Fietz, \& Schäfer, 1983). Only on the basis of the present experiments, however, can the US-preexposure effect be added unequivocally to the rapidly growing list of vertebrate learning phenomena found in honeybees. Although resemblances of this sort in the performance of animals as distantly related as rats and honeybees may well turn out to be no more than superficial (Bitterman, 1975), our data suggest that the dynamics of the US-preexposure effect are at least in some measure the same. Contextual conditioning is implicated, and its role seems to be an associative one; the conditioned context does not simply reduce response to the signal, but retards conditioning of the signal. Furthermore, signaling the US reduces conditioning of the context. How far the similarity goes is an interesting question. The retardation itself must be explained in terms of the mechanisms of compound conditioning, which are not yet very well understood even in vertebrates and which seem at the moment almost as complicated in honeybees (Couvillon \& Bitterman, 1982; Couvillon, Klosterhalfen, \& Bitterman, 1983).

\section{REFERENCES}

Abramson, C. I. (1986). Aversive conditioning in honeybees (Apis mellifera). Journal of Comparative Psychology, 100, 108-116.

Abramson, C. I., Bitterman, M. E. (1986). Latent inhibition in honeybees. Animal Learning \& Behavior, 14, 184-189.

Ayres, J. J. B., Bombace, J. C., Shurt lefF, D., \& Vigortto, M. (1985). Conditioned suppression tests of the context-blocking hypothesis: Testing in the absence of the preconditioned context. Journal of Experimental Psychology: Animal Behavior Processes, 11, 1-14.

Baker, A. G., Mercier, P., Gabel, J., \& Baker, P. A. (1981). Contextual conditioning and the US preexposure effect in conditioned fear. Journal of Experimental Psychology: Animal Behavior Processes, 7, 109-128.

Balsam, P. D. (1985). The functions of context in learning and performance. In P. D. Balsam \& A. Tomie (Eds.), Context and learning (pp. 1-21). Hillsdale, NJ: Erlbaum.

Balsam, P. D., \& SchWarTz, A. L. (1981). Rapid contextual conditioning in autoshaping. Journal of Experimental Psychology: Animal Behavior Processes, 7, 382-393.

BitTERMAN, M. E. (1975). The comparative analysis of learning. Science, 188, 699-709.

Bitterman, M. E., Menzel, R., Fietz, A., \& Schäfer, S. (1983). Classical conditioning of proboscis extension in honeybees (Apis mellifera). Journal of Comparative Psychology, 97, 107-119.

Bouton, M. E., KING, D. A. (1986). Effect of context on performance to conditioned stimuli with mixed histories of reinforcement and nonreinforcement. Journal of Experimental Psychology: Animal Behavior Processes, 12, 4-15.

Couvillon, P. A., Bitterman, M. E. (1982). Compound conditioning in honeybees. Journal of Comparative \& Physiological Psychology, 96, 192-199.

Couvillon, P. A., Klosterhalfen, S., \& Bitterman, M. E. (1983). Analysis of overshadowing in honeybees. Journal of Comparative Psychology, 97, 154-166.

GibBon, J., \& BalsaM, P. (1981). Spreading association in time. In C. M. Locurto, H. S. Terrace, \& J. Gibbon (Eds.), Autoshaping and conditioning theory (pp. 219-253). New York: Academic Press.

Grau, J. W., \& Rescorla, R. A. (1984). Role of context in autoshaping. Joumal of Experimental Psychology: Animal Behavior Processes, 10, 324-332.

Hinson, R. E. (1982). Effects of UCS preexposure on excitatory and inhibitory rabbit eyelid conditioning: An associative effect of conditioned contextual stimuli. Journal of Experimental Psychology: Animal Behavior Processes, 8, 49-61.

Kremer, E. F. (1972). Properties of a preexposed stimulus. Psychonomic Science, 27, 45-47.

LuBow, R. E. (1973). Latent inhibition. Psychological Bulletin, 79, 398-407. 
RANDICH, A. (1981). The US preexposure phenomenon in the conditioned suppression paradigm: A role for conditioned situational stimuli. Learning \& Motivation, 12, 321-341.

RANDiCH, A., \& LoLoRDo, V. M. (1979). Associative and nonassociative theories of the UCS preexposure phenomenon: Implications for Pavlovian conditioning. Psychological Bulletin, 86, 523-548.

RANDICH, A., \& Ross, R. T. (1984). Mechanisms of blocking by contextual stimuli. Learning \& Motivation, 15, 106-117.

ReISs, S., \& WAGNER, A. R. (1972). CS habituation produces a "latent inhibition effect" but no active "conditioned inhibition." Learning \& Motivation, 3, 237-245.

ResCorla, R. A. (1971). Summation and retardation tests of latent in- hibition. Journal of Comparative \& Physiological Psychology, 75, 77-81.

Rescorla, R. A., \& Wagner, A. R. (1972). A theory of Pavlovian conditioning: Variations in the effectiveness of reinforcement and nonreinforcement. In A. H. Black \& W. F. Prokasy (Eds.), Classical conditioning II: Current research and theory (pp. 64-99). New York: Appleton-Century-Crofts.

SHISHIMI, A. (1985). Latent inhibition experiments with goldfish (Carassius auratus). Journal of Comparative Psychology, 99, 316-327.

(Manuscript received April 15, 1986; revision accepted for publication August 12, 1986.) 